\title{
FRONTEIRAS NA INVESTIGAÇÃO DA ESQUIZOFRENIA
}

\author{
Marcelo Blaya*
}

As reações psicopatológicas incluídas sob o rótulo de esquizofrenia compreendem quadros clínicos bastante diferentes entre si. Apesar disso e da discordância de opiniōes, a maioria dos autores aceita o conceito formulado por Bleuler 6, em 1911: "Pelo nome "demência precoce" ou "esquizofrenia" designamos um grupo de psicoses cujo curso é, às vêzes, crônico e, outras vêzes, marcado por ataques intermitentes, podendo estacionar ou regredir em qualquer fase, sem completa restitutio ad integrum". Bleuler classificou os sintomas esquizofrênicos em fundamentais e acessórios: fundamentais são as perturbações de associação de idéias e de afetividade, a ambivalência, o autismo, as alterações da atenção e da vontade; acessórios são as alucinações, as idéias delirantes e uma variedade de sintomas somáticos e psicológicos.

É óbvia a importância médico-social da esquizofrenia. Trata-se de enfermidade que geralmente atinge pessoas jovens; tem evolução lenta e é de difícil tratamento, o que explica a elevada percentagem de pacientes esquizofrênicos na população dos hospitais psiquiátricos.

As investigações relativas à esquizofrenia tem seguido caminhos diversos, dividindo-se, de modo geral, os pesquisadores em organicistas e de orientação psicológica. Uma revisão excelente das pesquisas efetuadas em tôrno dos aspectos somáticos da esquizofrenia foi publicada por Richter ${ }^{39}$. Bellak ${ }^{3,4}$ revisou a bibliografia da esquizofrenia até 1957 . É grande o número de trabalhos publicados por investigadores com orientação psicológica: citaremos, como contribuições que nos parecem mais relevantes, as de Federn ${ }^{10}$, Fromm-Reichmann ${ }^{12}$, Knight ${ }^{22,}{ }^{23}$, Sechehaye ${ }^{41}$, Wexler 44 e Rosen ${ }^{40}$.

Apesar de certo antagonismo entre as correntes somatogênicas e psicogênicas, parece haver acôrdo quanto à influência mútua de fatôres biológicos e psicológicos, aceitando-se que as alterações psicológicas tenham uma correspondência no substrato anátomo-fisiológico, especialmente no sistema nervoso central.

Parte dêste trabalho foi apresentado à Sociedade de Neurologia, Psiquiatria e Neurocirurgia do Rio Grande do Sul.

* Ex-interno do Michael Reese Hospital (Chicago, Illinois); ex-fellow da Menninger School of Psychiatry (Topeka, Kansas); ex-residente em Psiquiatria do Topeka State Hospital e do Larned State Hospital; Diretor da Clínica Pinel (Pôrto Alegre, Rio Grande do Sul). 
Nesta apresentação pretendemos revisar a contribuição de três grupos de investigadores que julgamos representarem tendências caracteristicas da investigação neste setor e cujos trabalhos encerram grandes esperanças para a solução futura dêste problema. Um dos grupos o aborda do ponto de vista biológico, e os outros dois trabalham em problemas psico-sociais relacionados com a esquizofrenia, particularmente problemas familiares.

\section{iNVESTIGAÇÕES NA TULANE UNIVERSITY (NEW ORLEANS)}

Os efeitos da mescalina sôbre sêres humanos foram estudados por Beringer" que, em 1927, publicou extensa monografia sôbre o assunto; êsse estudo, entretanto, passou despercebido. O mesmo ocorreu com a publicação de Hofman, em 1943, sôbre cs efeitos da ingestão acidental de pequena quantidade de LSD-25. Stoll 4? publiccu, em 1947, os resultados obtidos com o LSD-25 em voluntários "normais" e em psicóticos. O interêsse nessas publicaçōes isoladas aumentou consideràvelmentc, a partir do trabalho de Osmond e Smythies ${ }^{35}$. chamando a atenção para a semelhança de estrutura quimica entre a mescalina, a adrenalina e a noradrenalina; êstes autores sugeriram que uma substância intermediária entre a mescalina e a adrenalina - substāncia $M$ - resultante da metabolização defeituosa da adrenalina, poderia ser responsável por certos aspectos aparentemente tóxicos, das reações esquizofrênicas. Poder-se-ia atribuir a falha da metabolizaçāo da adrenalina a uma deficiencia no sistema enzimático, ligada a um fator genético, como foi postulado por Kallman 12. Ulteriormente Hoffer ${ }^{20}$ encontrou quantidades elevadas de adrenocromo no sôro de pacientes esquizofrênicos e de pacientes "normais" que haviam recēido LSD-25 e sugeriu que essa substância fôsse a $M$ de Osmond. Hoffer injetou adrenocromo em voluntários, determinando quadro sintomatológico que lembrava o de pacientes esquizofrênicos agudos; declararam êsses voluntários haver perdido o contrôle sôbre suas alucinações e idéias delirantes, julgando que tais experiências eram reais. Essa falta de insight não ocorre quando se administra o LSD-25 e a mescalina.

Os trabalhos mencionados foram levados a cabo por pesquisadores familiarizados com as teorias psicológicas mas sem treino e prática intensiva nesse setor. A situação é muito diferente com o grupo da Tulane University (New Orleans), liderado por Robert Heath. Além de sua formação médica, neurológica e psiquiátrica, Heath tem formação psicanalitica e, durante muitos anos, investigou correlações entre fenômenos mentais e funções cerebrais. As bases teóricas do grupo da Tulane são as formuladas por Rado ${ }^{37}$.

Heath demonstrou, com experiências em macacos, a existência de correlação entre a atividade do sistema limbico e a conduta dos animais. Quando a região septal e a porção anterior do hipocampo são destruídas, os animais apresentam alteraçoes de conduta e da postura que lembram as que ocorrem em pacientes catatônicos agudos; a estimulação elétrica dessas áreas torna os animais interessados no ambiente, alertas, havendo diminuição do tono postural. Partindo dêsses trabaIhos, foram desenvolvidas técnicas estereotáxicas de implantação de electrodos subcorticais. De 1950, quando foram iniciadas as pesquisas em sêres humanos, até 1959, Heath estudara um total de 52 indivíduos, alguns por mais de dois anos (42 esquizofrênicos crônicos, 4 epilépticos, 6 "normais"), demonstrando haver estreita correlaçāo entre a atividade elétrica da regiāo septal e do hipocampo com a conduta psicótica dos enfermos. Pacientes agitados e hiperirritados exibiam alteraçōes dos traçados obtidos na região da amígdala e da porção anterior do hipocampo, enquanto fenômenos catatônicos cioncidiam com alterações de traçados obtidos na região septal; traçados obtidos mediante electrodos implantados em outras áreas subcorticais e corticais, e, bem assim, o electrencefalograma convencional, nāo exibiam quaisquer alterações. Traçados semelhantes aos colhidos de pacientes em fase 
aguda foram obtidos em pacientes não-psicóticos que haviam recebido mescalina e LSD-25. O paralelismo entre essas alterações bioelétricas e as perturbações de consciência e de percepção era estreito. Essas investigações mostram a existência, na opiniāo de Heath, de uma relação entre os processos básicos que ocorrem na esquizofrenia e na epilepsia, principalmente nas chamadas epilepsias psicomotoras. Os sintomas clínicos de ambas se assemelham e o diagnóstico diferencial é, às vêzes, dificil. Na prática, recorre-se ao electrencefalograma; porém, como foi dito acima, perturbaçōes elétricas profundas podem não ser registradas no electrencefalograma convencional.

A estimulação elétrica da região septal produz efeitos de duraçāo fugaz, especialmente estados eufóricos. A estimulação de outras áreas subcorticais não produziu essa euforia, e, em algumas regiões, determinou sensações vagas de mal-es$\operatorname{tar}{ }^{13},{ }^{14}, 16,34$.

Simultâneamente foi investigada a propriedade que tem o sôro de esquizofrênicos de oxidar a adrenalina a uma velocidade maior que a do sôro de pacientes contrôles não-esquizofrênicos. Essa propriedade é comum ao sôro de outros pacientes que sofrem de doenças orgânicas crônicas. O enzima responsável por essa oxidação é a ceruloplasmina, uma globulina ligada à quase totalidade do cobre encontrado no sôro ${ }^{24}$. Ao tentar isolar a ceruloplasmina, Heath e outros ${ }^{18}$ obtiveram uma fração que diferia da isolada de sôro de pacientes não-esquizofrênicos. Quando injetada em macacos, essa substância produzia alteraçōes elétricas semelhantes às registradas em pacientes psicóticos em fase aguda; injetada em voluntárjos humanos, inclusive médicos, determinou sintomas que reproduziram os apresentados e descritos por pacientes esquizofrênicos. Assim foi descoberta a taraxeina, sendo sugerido que esta substância endógena, capaz de produzir alterações específicas em áreas subcorticais, fôsse a substância $M$ prevista por Osmond. Heath acredita que a taraxeina seja uma proteina anormal resultante da interação de fatôres genéticos e fatôres estressantes internos ou externos ${ }^{17},{ }^{19}$. De acôrdo com Heath, o esquizốrènico é um indivíduo com um defeito básico de integração da personalidade resultante de uma falha de integração neurológica, possivelmente sináptica; esta insuficiência ao nível das sinapses seria ocasionada por anomalias dos sistemas enzimáticos.

As investigações de Heath e colaboradores têm despertado grande interêsse, especialmente na América do Norte. Até ao presente momento, dois laboratórios norte-americanos e um sueco conseguiram reproduzir os experimentos que envolvem a taraxeina ${ }^{33}$.

\section{INVESTIGAÇÕES NO "CENTRO DE ESTUdOS FAMILIARES" (BETHESDA)}

O conhecimento das dificuldades familiares em casos de esquizofrenia levou Bowen a internar, em secçōes especiais, pacientes esquizofrênicos e o progenitor a quem o enfêrmo se ligava mais estreitamente. $\mathrm{Na}$ fase inicial da pesquisa foram internados três adolescentes esquizofrênicos e suas mães para observação direta da interaçāo e o tratamento, que consistia em psicoterapia individual para o paciente e sua mãe. Bowen ${ }^{\top}$ observou que ambos passavam por ciclos intensos de combinações, como se não houvesse barreiras definidas entre o Ego do paciente e o da mãe; esta fusāo chegava ao ponto de produzir perda de identidade, um julgando-se o outro. Depois dessa combinação intensa havia uma fase de separação, quando o paciente e sua mãe procuravam estabelecer o mesmo tipo de relações com outros individuos. Pareciam nāo ter consciência da intensidade e da periodicidade dessas alterações. O tratamento psicoterápico instituido servia para estabilizar as relações do par num ponto de coexisténcia confortável, sem a intenção de resolver a intensa relação simbiótico-parasitáría existente.

Nestes pares, Dysinger ${ }^{\theta}$ observou um tipo de comunicação pré-verbal caracteristico, ao qual chamou "diálogo por atuação", baseado em movimentos de apro- 
ximação feitos pelo paciente ou por sua mãe; tais movimentos de aproximação são inconscientes e, nesse plano, aceitos ou rejeitados. A observação de um par durante um periodo de 6 meses, tabulado o tipo de aproximações e respostas, permitiu a Dysinger estabelecer certas variações ciclicas nessas comunicações. Contrastando esta forma de comunicação com a verbal concomitante, viu-se a não-coincidência dos conteúdos comunicados e dos problemas assoclados. Esse diálogo entre a paciente e a mãe parece ser realizado em nivel inconsciente, envolvendo processos primários, enquanto as comunicaçoes verbais são mais elaboradas e do tipo dos processos secundários.

Bowen chegou à conclusão de que o par estudado inicialmente era apenas parte de um grupo patológlco malor, a familia. Assim, numa segunda fase da pesquisa, sete familias com um filho ou filha esquizofrênicos foram viver numa enfermaria especial para o estudo clínico e o tratamento dêsses grupos familiares. A terapêutica consistia, principalmente, de psicoterapia psicanalitica de grupo, envolvendo todos os membros da familia. Os "normais" continuaram suas atividades de rotina, e o grupo passou a ser visto, dfăriamente, em reuniōes com o terapeuta da família. A equipe da enfermaria fol instruida para lidar com a familia como um todo, desencorajando as tentativas de resolver problemas "individuais" isoladamente.

E notória, nestas famílias, a ausência de um dos cônjuges, geralmente o pai, no processo de tomar decisões que dizem respeito à familia e seus membros. Quando, no tratamento, êsse membro retraido pode ser trazido de volta a desempenhar o papel que the compete dentro do grupo familiar, há gradual dissolução do par formado pelo paciente com o outro cônjuge.

Outra observação feita por Bowen, corroborando hipóteses aventadas por outros, é a que chamariamos "efeito de gangorra" 1. O progresso clínico "isolado" de um paciente faz-se em detrimento do equilibrio homeostático no Ego do progenitor (ou cônjuge) a êle ligado de forma simbiótica. A família, como um todo, está doente, e a sintomatologia psicótica pode ser descarregada através de um de seus membros.

Estes pacientes têm dificuldades em aproximar-se emocionalmente dos demais membros da familia, pôsto que estas aproximaçōes são seguidas por manobras de isolamento e distanciamento, posslvelmente motivadas por impulsos incestuosos conscientes ou pelo temor de ser englobado pelo outro familiar. Para que esta aproximação ocorra, é necessário que o paciente se sinta seguro de sua posição na familia e que os papéis dos demais membros estejam claramente definidos ${ }^{8}$.

\section{INVESTIGACOES NA YALE UNIVERSITY (NEW HAVEN)}

Lidz e col. ${ }^{26},{ }^{27},{ }^{28},{ }^{29}$ estudaram minuciosamente, durante anos, as familias de 16 esquizofrênicos adolescentes. De suas observações inferiram que há certars constantes nessas familias com relação à personalidade dos pais, à desorganização da estrutura familiar, a um tipo especial de transmissão de padrões de irracionalidade dentro da familia e, derivadas das anteriores, certa universalidade de problemas incestuosos e homossexuais.

Um progenitor ou ambos lutam para manter seu próprio equilibrio emocional e recorrem à distorção da realidade externa a fím de enqus drá-la dentro de seu esquema inflexível de um mundo externo preconcebido. Em. nove das dezesseis familias estudadas, pelo menos um dos progenitores era esqrizofrênico. Os não-esquizofrênicos se mostravam mais ou menos refratários às emoções e necessidades de outros individuos, especialmente do cônjuge e dos filhos. Essa atitude parecia constituir uma defesa que não permitia intromissão de r,ensamentos ou percepcôes que ameaçassem perturbar o equilibrio caractereológico típico dêsses indivíduos.

Lidz observou que a desorganização dentro ciessas familias é ocasionada pela inobservância dos limites das diferentes gerações envolvidas e do respeito às fun- 
çōes dos membros, levando em consideração os respectivos sexos. Parsons ${ }^{30}$ estudou o funcionamento de núcleos familiares do ponto de vista psicanalitico e, através de suas conclusões, compreende-se melhor os pontos onde a desorganização acima mencionada é mais conspicua. Parsons frisa a precariedade do equilibrio existente dentro de todos os grupos familiares entre as relações eróticas essenciais à coesão do núcleo familiar e ao desenvolvimento normal da criança, e, por outro lado, os impulsos incestuosos que tendem a desorganizar a familia. Uma das funções básicas do grupo familiar é a deserotizaçã, das relações mãe-filho ou pai-filha, o que em nomenclatura psicanalítica se expressa dizendo que o conflito edípico foi solucionado satisfatoriamente. O papel central que êsse conflito desempenha nas coletividades humanas, deve-se ao fato de gue a criança tem de atravessar êsse fio de navalha, havendo tragédia em ambos ss lados. Problemas graves decorrem da falta de investimento libidinoso, por parte dos pais, na criança durante as fases pré-fálicas. Por outro lado, a perseverança de relações eróticas durante a fase de latênrı, e após a mesma, resulta em. problemas graves para a manutenção do núcleo familiar.

No quadro 1 são comparadas as funçōes essenciais apontadas por Parsons em familias normais, e as falhas mais freqüentes apontadas por Lidz nas framilias de esquizofrênicos.

Requisitos essenciais na organização o função de familias normais (Parsons)
Perturbaçōes mais freqüentes nas familias de pacientes esquizofrênicos

( Lidz)
1. Respeito aos limites entre gerações.

2. Os pais assumem papéis de acôrdo com seu sexo, como pai e mãe, $\theta$ de acôrdo com as principais exigências do grupo.

3. Relações harmônicas complementares entre os pais.

4. Os pais auxiliam os filhos a deserotizar relaçōes antes da fase de latência, e na desincestualização de objetos sexuais durante a adolescência.

5. Os padrōes de comunicação intrafamiliar devem ser flexiveis, permitindo seu uso indiscriminado dentro e fora do grupo famillar.
1. Violação dêsses limites.

2. Os pais têm identificações sexuais mal definidas. Pai e mãe confusos quanto aos seus respectivos papéis. Em algumas familias falta um núcleo familiar.

3. Cônjuges separados, física ou emo- cionalmente.

4. Sedução parental é iniciada ou continuada na fase de latência. Sedução reiniciada durante a adolescência.

5. Familias geralmente isoladas da comunidade. Comunicações dependem grandemente de sinais não-verbais. Impulsos homossexuais e heterossexuais inconscientes transmitidos desta forma.

Quadro 1 - Paralelo entre as conclusões de Parsons quanto ao funcionamento de familias normais $e$ as de Lidz em familias de esquizofrênicos. 
Violações de limites entre gerações de pais e filhos destroem a estrutura familiar essencial ao contrôle inconsciente de impulsos incestuosos por parte dos componentes de ambas as gerações. Isso ocorre, quando, por exemplo, um dos espôsos se comporta em relação ao outro como um filho, rivalizando com a criança na obtenção das atençōes do pai ou da mãe. O mesmo acontece quando um dos cônjuges utiliza a criança para substituir o outro. Para isso pode haver uma luta surda entre os pais, movendo-se campanhas de descrédito com o intuito de obter a aliança com o filho. O equilibrio em tais familias é alcançado, recorrendo-se a essas anomalias de funçōes parentais, e pode chamar-se de equilibrio psicótico.

Pais psicóticos dificultam à criança estabelecer os limites de seu Ego; custa-lhe a percepção clara de suas necessidades e das dos pais, o que resulta numa confusão e difusão de papéis. Num caso mencionado por Lidz, essa confusão ia ao ponto de o filho pôr á mãe nos joelhos e dar-lhe palmadas para castigá-la, e a mãe nảo só aceitar êsse castigo, mas não permitir que o pai interferisse.

A impossibilidade de assumirem êsses progenitores, em relação aos filhos, atitudes compativeis com seu sexo e com os hábitos do agrupamento humano, decorre da identificação confusa que fizeram em relação à sua própria família. É necessário que o progenitor que vai servir de modêlo para identificação sexual dos filhos tenha uma situaçāo definida em relação a si mesmo. Na impossibilidade de resolver essa situação com os país, os pacientes de Lidz tinham uma perturbaçāo no balanço de tenđências hétero e homossexuais, não encontrando uma situação livre de conflito dentro do grupo familiar.

O problema da homossexualidade que, desde a discussão do caso Schreber ${ }^{11}$, parece ligado ao da esquizofrenia, é estudado por Lidz em conjunção com as tendências incestuosas. Lidz não crē que as fantasias incestuosas e homossexuais conscientes de seus esquizofrênicos sejam explicáveis apenas como sintomas de regressão. Como vimos acima, Parsons aponta a necessidade de uma deserotização mais ou menos completa das relaçōes mãe-filho e pai-filha, durante a fase de latência, permitindo que a criança faça uma identificação com o progenitor do mesmo sexo e que use as cargas libidinosas liberadas para investi-las nos processos de aprendizado e de formação de relações interpessoais fora do círculo familiar, especialmente na escola. Nas familias estudadas por Lidz tal não ocorre. A constelação familiar mais freqüente é aquela em que o progenitor do sexo oposto assume uma atitude sedutora consciente ou inconsciente, ao passo que o progenitor do mesmo sexo tem uma atitude indiferente. A ausência de experiencias frustrantes que forcem o paciente a deserotizar a relação objetal primária com os progenitores explicaria a perseverança das idéias incestuosas e homossexuais conscientes e a tendência que se vê nestes pacientes de sexualizar tôdas as suas relaçôes objetais. As fantasias incestuosas impelem o paciente ao pânico, e o temor de ser dominado por elas leva-o a estabelecer manobras defensivas de segurança, que Lidz crê coincidirem com os sintomas primários de Bleuler. Por parte dos pais, especialmente daquele com quem o paciente estabelece a relação simbiótica, há uma necessidade inconsciente de perpetuar essa situação ${ }^{25,30,88,43}$.

\section{COMENTÁRIOS}

É satisfatório verificar o interêsse crescente que psiquiatras com orientação psicanalítica têm demonstrado por trabalhos de investigação envolvendo o substrato biológico dos fenômenos mentais, como nos casos de Heath, Masserman ${ }^{32}$, Margolin ${ }^{31}$ e outros. Não se pretende, como querem os simplistas, ver nisso uma solução final exclusivamente biológica ou psicológica. Freud, que tinha excelente formação médica, especialmente neurológica, nunca perdeu de vista o fato de existir uma correlação entre o aparelho mental por êle delineado e as estruturas somáticas. 
Em relação aos problemas da esquizofrenia, essa aproximação multidisciplinar é mandatória. Os trabalhos de Kaliman ${ }^{21}$ com gêmeos univitelinos parecem indicar claramente a participação de fatôres genéticos na etiologia da esquizofrenia. Parece lógico que fatôres anatômicos, bioquímicos, fisiológicos e endócrinos devam ter um papel, apesar de os métodos usados, até há poucos anos, não terem permitido uma conclusão a êsse respeito. Não faz muito que os fatôres bioquímicos e a produção das "psicoses modelos" têm permitido um estudo mais preciso de algumas das variações que ocorrem em pacientes esquizofrênicos.

Até que ponto essas pesquisas auxiliarão na correção terapêutica, é uma questão aberta. Os resultados promissores, apresentados por Heath ${ }^{15}$, com o uso de extrato bovino de porçōes cerebrais (região septal), no tratamento de enfermos esquizofrênicos, aguardam confirmação.

Citemos, no caso das investigações com drogas capazes de produzir sintomas semelhantes aos da esquizofrenia, que um dos seus usos imediatos é a facilitação do ensaio biológico das novas drogas a serem introduzidas na terapêutica psiquiátrica.

Nas investigaçōes psicanalíticas relacionadas com a esquizofrenia há uma mudança radical de foco, da psicopatologia individual para a familiar. Se o tratamento de pacientes neuróticos pode ser feito sem a participação da família, a maioria dos autores concorda em que tal não é possível quando se trata de pacientes esquizofrênicos. Os trabalhos de Bowen parecem confirmar outras observações, principalmente de Lidz, de que o problema deve ser encarado em têrmos de uma família doente e não apenas de um indivíduo enfêrmo.

As conclusões a que chegou Lidz hão que ser apreciadas com certo cuidado no que diz respeito às relações intrafamiliares anômalas, sobretudo quanto ao papel por êle atribuído aos impulsos incestuosos conscientes dêstes enfermos; êste autor chama a atenção para o fato de não considerar essa situação como a causal para esquizofrenia. Lidz crê não se tratar de fantasias regressivas do doente e, sim, da resultante de uma situação criada e alimentada pelas funções distorcidas que os pais desempenham dentro dessas famílias. Bateson 2, na discussão de uma apresentação feita por Lidz, vê nesse fenômeno um tipo de pantalha onde o paciente projeta dificuldades caracterìsticamente orais, verbalizadas em têrmos fálicos, incestuosos ou homossexuais. Estas manifestações visariam encobrir terrores mais sérios relacionados com as intensas frustrações orais e as fantasias de abandono e deamparo que as acompanham.

\section{RESUMO}

O conceito bleuleriano de esquizofrenia continua a ser o mais acatado pelos investigadores. Apesar da existência de correntes nìtidamente biológicas ou psicológicas nota-se, nos trabalhos de pesquisa, uma tendência marcadamente psicobiológica. No presente trabalho são discutidos os resul- 
tados obtidos por três grupos de investigadores, um operando com variáveis biológicas, e os outros dois, com variáveis de relação interpessoal, especialmente infrafamiliares.

O primeiro grupo é liderado por Heath que tem chamado a atenção para a atividade bioelétrica anormal de certas estruturas subcorticais (região septal e hipocampo) em relação às variações posturais e de conduta, tanto em macacos como em sêres humanos. $O$ isolamento de uma proteina específica no sôro de pacientes esquizofrênicos, capaz de produzir sintomas em voluntários injetados com êsse material, parece mostrar que existe uma falha metabólica, possivelmente enzimática, nesses pacientes.

Os outros dois grupos, liderados por Bowen e Lidz, estudam caracteristicas das funções e interrelações em famílias com pacientes esquizofrênicos. As conclusões de ambos os grupos apoia o conceito de famílias esquizofrênicas contra o ponto de vista clássico de pacientes esquizofrênicos.

\section{SUMMARY}

Schizophrenia: advances in research.

Bleuler's concept of schizophrenia is up till now the most widely accepted by the investigators. In spite of trends of research clearly biological or psychological, there is a tendency for a clear cut psychobiological approach or, even better, for a multidisciplinary study of the problem. In this paper are discussed the results obtained by three groups of researchers. One deals with biological variables while the other two work with interpersonal relations, mostly intrafamilial ones.

The first is the Tulane group. Heath, in charge of the project, has stressed that abnormal bioelectrical activity of certain subcortical areas, mainly the septal region and the hippocampus, is related to postural and behavioral variations in monkeys and humans. The isolation of a protein from the serum of schizophrenic patients, that produces schizophrenic-like symptoms in voluntaries when injected with this substance, tries to prove the existence of a metabolic error, probably enzymatic, in these patients.

The other two groups (Bethesda and Yale), with Bowen and Lidz, are studying characteristics of the functions and interrelations in families with one schizophrenic patient mainly adolescent. The conclusions arrived by both groups of researchers support the concept of a schizophrenic family vs. the classical concept of a schizophrenic patient.

\section{REFERENCIAS}

1. Albuquerque, M. A. - Comunicação pessoal. 2. BATESON, G. - Discussão no livro compilado por J. H. Massermann: Individual and Family Dynamics. Grune \& Stratton, Nova York, 1959. 3. BELLAK, L. - Dementia Praecox. Grune \& Stratton, Nova York, 1948. 4. BELI.AK, L. - Schizophrenia: A Review of the Syndrome. 
Logos Press, Nova York, 1958. 5. BERINGER, K. - Der Meskalinrausch. Monogr. Neurol. Psychiat., 1927. 6. BLEULER, E. - Dementia Praecox or the Group of Schizophrenias. International Universities Press, Nova York, 1950. 7. BOWEN, M. - Family participation in schizophrenia. Apresentado ao $113^{\circ}$ Congresso da Am. Psychiat. Ass., Chicago, 1957. 8. BOWEN, M. - A Family Concept of Schizophrenia. No livro compilado por D. D. Jackson: Etiology of Schizophrenia. Basic Books, Nova York, 1959. 9. DYSINGER, R. H. - The "action dialogue" in an intense relaticnship: A study of a schizophrenic girl and her mother. Apresentado no $113^{\circ}$ Congresso da Am. Psychiat. Ass.; Chicago, 1957. 10. FEDERN, P. - Principles of psychotherapy in latent schizophrenia. Am. J. Psychother, 1:129, 1947. 11. FREUD, S. - Psychoanalytic Notes upon an Autobiographical Account of a Case of Paranoia. collected Papers, vol. III, Hogarth Press, Londres, 1924. 12. FROMM-REICHMANN, F. - Psychotherapy of schizophrenia. Am. J. Psychiat., 111:410, 1954. 13. HEATH, R. G. - Studies in Schizophrenia: A Multiōisciplinary Approach to Mind-Brain Relationships. Harvard University Press, Cambridge, Mass., 1954. 14. HEATH, R. G. - Correlations between levels of psychological awareness and physiological activity in the central nervous system. Psychosom. Med., 17:385, 1955. 15. HEATH, R. G. - Pharmacological and biological approaches to psychotherapy. Apresentado ao 113' Congresso da American Psychiatric Ass., Chicago, 1957. 16. HEATH, R. G. Correlation of electrical recordings from cortical and subcortical regions of the brain with abnormal behavior in human subjects. Confinia Neurol., 18:305, 1958.17. HEATH, R. G.; LEACH, B. E.; COHEN, M. - Relationship of Psychotic Behavior and Abnormal Substances in Serum. No A.R.N.M.D.: The Effect of Pharmacologic Agents on the Nervous System. Williams \& Wilkins, Baltimore, 1959. 18. HEATH, R. G.; LEACH, B. E.; MARTENS, S.; COHEN, M. - Studies in mind-brain relationships: behavioral changes with administration of Taraxein, a substance extracted from schizophrenic serum. Apresentado ao $112^{\circ}$ Congresso da American Psychiatric Ass., Chicago, 1956. 19. HEATH, R. G.; COHEN, S. B.; SILVA, F.; LEACH, B. E.; COHEN, M. - Administration of Taraxein in humans. Dis. Nerv. Syst., 20:5, 1959. 20. HOFFER, A.; OSMOND, H.; SMYTHIES, J. - Schizophrenia: A new approach. J. Ment. Sc., 100:29, 1954. 21. KALLMAN, F. J. - Heredity in Health and Mental Disorders. W. W. Norton, Nova York, 1953. 22. KNIGHT, R. P. - Psychotherapy in acute paranoid schizophrenia with successful outcome. Bull. Menninger Clin., 3: 81, 1939. 23. KNIGHT, R. P. - Psychotherapy of an adolescent catatonic schizophrenic with mutism. Psychiatric, 9:923, 1946. 24. LEACH, B. E.; HEATH, R. G. - The in vitro oxidation of epinephrine in plasma. A. M. A. Arch. Neurol, \& Psychiat., 76:444, 1956. 25. LIDZ, R. W.; LIDZ, .T. - Therapeutic Considerations arising from the Intense Symbiotic Needs of Schizophrenic Patients in Psychotherapy with Schizophrenics. Em E. F. Brody e F. C. Redlich: Psychotherapy with Schizophrenics. International Universities Press, Nova York, 1952. 26. LIDZ, T. - Schizophrenia and the family. Psychiatry, 21:21, 1957. 27, LIDZ, T.; CORNELISON, A.; FLECK, S.; TERRY, D. - The intrafamilial environment of the schizophrenic patient: I. The father. Psychiatry, 20:329, 1957. 28. LIDZ, T.; CORNEIISON, A.; FLECK, S.; TERRY, D. - The intrafamilial environment of the schizophrenic patient: II. Marital schism and skew. Am. J. Psychiat., 114:241, 1957. 29. LIDZ, T.; CORNELISON, A.; FLECK, S.; TERRY, D. - The intrafamilial environment of the schizophrenic patient: VI. The transmission of irrationality. A. M. A. Arch. Neurol. \& Psychiat., 79:305, 1958. 30. LIMENTANI, D. - Symbiotic identification in schizophrenia. Psychiatry, 19:231, 1956. 31. MARGOLIN, S. G. - On some principles of therapy. Apresentado ao $113^{\circ}$ Congresso da Am. Psychiat. Ass., Chicago, 1957.32. MASSERMAN, J. H.; PETCHEL, C. T.; AARONS, L. - Effects of conflict and brain lesions in young vs. old animais. Apresentado ao $115^{\circ}$ Congresso da Am. Psychiat. Ass., Filadélfia, 1959. 33. MELANDER, B.; MARTENS, S. - A note on the mode of action of Taraxein and LSD. Dis. Nerv. Syst., 19:11, 1958. 34. MONROE, R. R.; HEATH, R. G.; MICKLE, W. A.; MILLER, W. H. - A comparison of cortical and subcortical brain waves in normal, barbiturate, reserpine and Chlorpromazine sleep. Ann. N.Y. Acad. Sci., 61:56, 1955. 35. OSMOND, H.; SMYTHIES, J. - Schizophrenia: 
A new approach. J. Ment. Sc., 98:309, 1952. 36. PARSONS, T.; BALES, R. - The Family. Free Press, Glencoe (Illinois) 1955. 37. RADO, S. - Dynamics and classification of disordered behavior. Am. J. Psychiat., 110:406, 1953. 33. REICHARD, S.; TILLMAN, C. - Patterns of parent-child relationships in schizophrenia. Psychiatry, 13:247, 1950. 39. RICHTER, D. - Schizophrenia: Somatic Aspects. Pergamon Press, Londres, 1957. 40. ROSEN, J. N. - Direct Analysis: Selected Papers. Grune \& Stratton, Nova York, 1953. 41. SECHEHAYE, M. A. - Symbolic Realization. International Universities Press, Nova York, 1951. 42. STOLL, W. - Lysergsäure-diäthylamid, ein Phantastikun aus der Mutterkorngruppe. Schweitz. Arch. Neurol, u. Psychiat., 60:1, 1947. 43. SZASZ, T. - A contribution to the psychology of schizophrenia. A. M. A. Arch. Neurol. a. Psychiat., 77:420, 1957. 44. WEXLER, M. - The structural problem in schizophrenia: therapeutic implication. Int. $J$. Psychoanal., 32:1, 1951.

Clinica Pinel — Av. Joūo Pessoa, 943 - Pôrto Alegre - Rio Grande do Sul. 